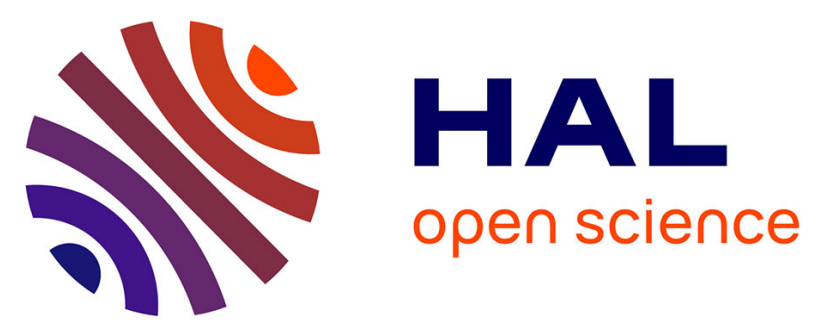

\title{
Spatiotemporal Dynamics of Morphological Processing in Visual Word Recognition
}

Eddy C Cavalli, Pascale Colé, Jean-Michel Badier, Christelle C Zielinski, Valérie C Chanoine, Johannes Ziegler

\section{- To cite this version:}

Eddy C Cavalli, Pascale Colé, Jean-Michel Badier, Christelle C Zielinski, Valérie C Chanoine, et al.. Spatiotemporal Dynamics of Morphological Processing in Visual Word Recognition. Journal of Cognitive Neuroscience, 2016, 28 (8), pp.1228 - 1242. 10.1162/jocn_a_00699 . hal-01470421

\section{HAL Id: hal-01470421 \\ https://hal-amu.archives-ouvertes.fr/hal-01470421}

Submitted on 17 Feb 2017

HAL is a multi-disciplinary open access archive for the deposit and dissemination of scientific research documents, whether they are published or not. The documents may come from teaching and research institutions in France or abroad, or from public or private research centers.
L'archive ouverte pluridisciplinaire HAL, est destinée au dépôt et à la diffusion de documents scientifiques de niveau recherche, publiés ou non, émanant des établissements d'enseignement et de recherche français ou étrangers, des laboratoires publics ou privés. 


\title{
Spatiotemporal Dynamics of Morphological Processing in Visual Word Recognition
}

\author{
Eddy Cavalli, Pascale Colé, Jean-Michel Badier, Christelle Zielinski, \\ Valérie Chanoine, and Johannes C. Ziegler
}

\begin{abstract}
The spatiotemporal dynamics of morphological, orthographic, and semantic processing were investigated in a primed lexical decision task in French using magnetoencephalography (MEG). The goal was to investigate orthographic and semantic contributions to morphological priming and compare these effects with pure orthographic and semantic priming. The time course of these effects was analyzed in anatomically defined ROIs that were selected according to previous MEG and fMRI findings. The results showed that morphological processing was not localized in one specific area but distributed over a vast network that involved left inferior temporal gyrus, left superior temporal gyrus, left inferior frontal gyrus, and left orbitofrontal
\end{abstract}

\section{INTRODUCTION}

In almost all languages, most words are morphologically complex, such as worker, which is composed of a stem (work) and a suffix (-er). Although the mapping between form and meaning is largely arbitrary (knowing that a word starts with the letter "p" does not tell us anything about its meaning), morphemes provide an interesting exception because words with common morphemes share both form (orthography) and meaning (semantics). Such systematic overlap makes it possible to establish a direct mapping between form and meaning. Understanding how morphologically complex words are processed and how the brain achieves the mapping between form and meaning represents a major challenge in reading research.

In this study, we used magnetoencephalography (MEG) to provide more precise information about the spatiotemporal dynamics of morphological processing. In particular, the goal was to investigate orthographic and semantic contributions to morphological priming and compare these effects with pure orthographic and semantic priming. Although many previous studies used masked priming because of their focused interest in the question of whether or not early morphological decomposition is semantically "blind" (e.g., Rastle \& Davis, 2008), here we used an unmasked priming task to ensure that primes

Aix Marseille Université and Centre National de la Recherche Scientifique gyrus. Second, all morphological effects were specific, that is, in none of the ROIs could morphology effects be explained by pure orthographic or pure semantic overlap. Third, the ventral route was sensitive to both the orthographic and semantic "part" of the morphological priming effect in the M350 time window. Fourth, the earliest effects of morphology occurred in left superior temporal gyrus around $250 \mathrm{msec}$ and reflected the semantic contribution to morphological facilitation. Together then, the present results show that morphological processing is not just an emergent property of processing form or meaning and that semantic contributions to morphological facilitation can occur as early as $250 \mathrm{msec}$ in the left superior temporal gyrus.

could actually activate semantic information (see also Smolka, Gondan, \& Rösler, 2015; Bozic, Marslen-Wilson, Stamatakis, Davis, \& Tyler, 2007).

This study was conducted in French, in which about 75\% of the words are morphologically complex (Rey-Debove, 1984). As in previous studies, we used the classic orthographic, semantic, and morphological priming conditions (e.g., Devlin, Jamison, Matthews, \& Gonnerman, 2004). However, the same targets were used in each condition to avoid potential confounds due to having different targets across the critical conditions (e.g., farmer-FARM vs. corner-CORN; see Feldman, Milin, Cho, Moscoso del Prado Martín, \& O'Connor, 2015). In addition, we systematically compared the morphological with both the orthographic and the semantic prime conditions to investigate the spatiotemporal nature of morphological priming when either orthography or semantics is controlled for (see Table 1). These morpho-orthographic $(\mathrm{M}+\mathrm{O}+$ ) and morphosemantic $(\mathrm{M}+\mathrm{S}+)$ effects were systematically contrasted with pure orthographic and pure semantic effects in the critical ROIs that have been identified in previous fMRI and MEG experiments (see below).

\section{Theoretical Background}

Over the past 30 years, an increasing body of research investigated morphological processing during visual word recognition (e.g., Crepaldi, Rastle, Coltheart, \& Nickels, 
Table 1. The Global Morphological Effect ( $M+$ vs. Unrelated) Was Contrasted with the $M+S+$ Effect (Morphological vs. Orthographic) and the $\mathrm{M}+\mathrm{O}+$ Effect (Morphological vs. Semantic) as well as Pure Orthographic (O+ vs. Unrelated) and Pure Semantic Priming (S+ vs. Unrelated) Effects

\begin{tabular}{lcccc}
\hline & \multicolumn{2}{c}{$M+S+$ Effect } & M+O+Effect \\
\cline { 2 - 4 } & Morphological & Orthographic & Morphological & Semantic \\
\hline $\mathrm{M}+$ & + & - & + & - \\
$\mathrm{O}+$ & + & + & + & + \\
$\mathrm{S}+$ & + & - & ourson (bear cub) & peluche (plush) \\
Prime & ourson (bear cub) & oursin (urchin) & ours (bear) & ours (bear) \\
Target & ours (bear) & ours (bear) &
\end{tabular}

Note that the same target is used across all conditions.

2010; Taft, 1979). It is well established that the recognition of a stem (e.g., part) is facilitated by the prior presentation of a morphologically related word (e.g., departure) and that such morphological priming cannot be explained by either orthographic or semantic overlap (Feldman, 2000; Rastle, Davis, Marslen-Wilson, \& Tyler, 2000). For quite some time, it had been assumed that complex words were decomposed into their constituents only if the complex word was related in meaning to its stem. For example, using fully visible primes, Rastle et al. (2000) showed that government primes govern (semantically transparent) but that department does not prime depart (semantically opaque).

Recent work, however, has challenged the view that morphological decomposition only takes place when there is a true semantic relationship between the complex word and its stem. Indeed, a bulk of masked priming studies have typically reported that the size of morphological priming for semantically transparent pairs (farmer$F A R M)$ is identical to that of semantically opaque or pseudoaffixed pairs (corner-CORN) and that both conditions are significantly different from nonmorphological orthographic controls (cashew-CASH; e.g., Beyersmann et al., 2015; Beyersmann, Castles, \& Coltheart, 2012; Lavric, Elchlepp, \& Rastle, 2012; Rastle \& Davis, 2008; Meunier \& Longtin, 2007). These findings have been taken to suggest that early morphological decomposition is semantically "blind." However, the form-then-meaning account has not gone uncriticized. Feldman, O'Connor, and Moscoso del Prado Martin (2009) pointed out that these findings rely on a null effect (absence of a difference between farmerfarm and corner-corn items). When they increased the statistical power by pooling data from different published masked priming experiments into a meta-analysis, they showed that morphological facilitation was significantly greater (+10 msec) for semantically similar (transparent) than semantically dissimilar (opaque) pairs (Feldman et al., 2009). Also, a recent study showed that semantically similar prime-target pairs can produce greater facilitation than semantically dissimilar pairs even at short prime durations when using the same targets across conditions
(Feldman et al., 2015). Together, these results were taken as evidence in favor of the form-with-meaning account, which suggests that orthographic and semantic information continually interacts when processing morphologically complex words (Feldman et al., 2009, 2015; Diependaele, Sandra, \& Grainger, 2009; Devlin et al., 2004).

\section{ERP Studies on Morphological Processing}

Given that the two main theoretical accounts (form-thenmeaning vs. form-with-meaning) make different predictions with respect to the timing of orthographic versus semantic contributions to morphological priming, it is not surprising that these accounts have extensively been tested in a variety of ERP studies (for a review, see Smolka et al., 2015). Most of these studies reported morphological priming effects to occur in two time windows, the N250 and the N400, when comparing morphologically related pairs (e.g., darker-dark) to an unrelated condition (Beyersmann, Iakimova, Ziegler, \& Colé, 2014; Morris, Grainger, \& Holcomb, 2008, 2013; Lavric, Clapp, \& Rastle, 2007; Morris, Frank, Grainger, \& Holcomb, 2007). However, different and somewhat inconsistent results have been obtained when morphologically related word pairs were compared with pseudocomplex pairs (e.g., corner-corn) or nonmorphological orthographic controls (e.g., brotbel-broth). Some studies found indeed no difference between morphological (farmer-FARM) and pseudomorphological primes (corner-CORN) during the early time N250 window (Morris et al., 2008, 2013; Lavric et al., 2012; Lavric, Rastle, \& Clapp, 2011; Morris, Porter, Grainger, \& Holcomb, 2011) in favor of early morphoorthographic segmentation. However, others reported differences between morphological primes and pseudomorphological or nonmorphological controls even in the early time window (Morris et al., 2007). In the N400 time window, some studies again found no differences between morphological and pseudomorphological primes (Lavric et al., 2007) whereas others reported greater priming for morphological than for pseudomorphological primes 
(Lavric et al., 2011; Morris et al., 2007). One key difference is with respect to prime visibility. Although Lavric et al. (2007) used masked primes, Lavric et al. (2011) used visible primes (200 msec). This suggests that the influence of semantics on morphological priming can be detected more easily when participants have enough time to process the prime.

Only a few studies have directly compared morphological and semantic priming. Recently, in French adult skilled readers, Beyersmann et al. (2014) found significant morphological (e.g., lavage-laver [washing-wash]) but no semantic (e.g., linge-laver [laundry-wash]) or orthographic (e.g., lavande-laver [lavender-wash]) priming in the 100-250 msec time window (P200). In the early N400, morphological priming was stronger than semantic priming, whereas no difference was found in a later portion of the $\mathrm{N} 400$. These results were taken to suggest that morphological priming is semantically blind in the first stage (Lavric et al., 2012; Morris et al., 2007; Longtin \& Meunier, 2005) but that morphosemantic information comes into play during a later process (Beyersmann, Coltheart, \& Castles, 2012; Diependaele et al., 2009; Diependaele, Sandra, \& Grainger, 2005).

\section{MEG Studies}

There is a quite extensive literature on morphological priming using MEG. Interestingly, most MEG studies used single word presentation rather than priming. MEG recordings to single word presentations typically show a number of clearly distinguishable components between 150 and $500 \mathrm{msec}$, the most prominent being the M170, M250, and M350 (Pylkkänen \& Marantz, 2003). Much of the MEG research investigated the sensitivity of these components to various psycholinguistic word properties. With respect to morphological processing, it has been found that the M170 response whose generators are located in inferior temporal cortex (i.e., Visual Word Form Area) was sensitive to morphological properties, such as affix frequency and the conditional probability of encountering a word given its stem (Lewis, Solomyak, \& Marantz, 2011; Solomyak \& Marantz, 2010). Lexical access for morphologically complex words is typically indexed by the M350 response (equivalent to the N400 response in ERPs) as supported by the fact that measures of lexical identity (i.e., lemma frequency or morphological family frequency) modulate the M350 in left middle and superior temporal cortex (Solomyak \& Marantz, 2010; Pylkkänen, Feintuch, Hopkins, \& Marantz, 2004). Interestingly, the M350 contains actually two peaks; the first peak, the M250, is sensitive to lexical components of morphologically complex words and the second peak, the M350, is an index of lexical access for the decomposed morphemes (Solomyak \& Marantz, 2010; Pylkkänen \& Marantz, 2003) and is also sensitive to semantic properties and whole word frequency (Pylkkänen, Stringfellow, \& Marantz, 2002).
In one of the most comprehensive studies, Fruchter and Marantz (2015) used a parametric approach, in which MEG components were correlated with corpus-based morphological and semantic measures. The results showed an early effect of derivational family entropy in left middle temporal gyrus and left superior temporal gyrus around $\sim 240 \mathrm{msec}$, which was interpreted as a stem lookup stage. This effect was followed by a surface frequency effect in left middle temporal gyrus around 430-500 msec, supporting the notion that suffixed words were decomposed into stems and affixes for recognition. Results also showed that the semantic coherence measure (i.e., the gradient semantic fit of stems and affixes) was localized in left orbitofrontal regions between $\sim 350$ and 500 msec. The results of Fruchter and Marantz (2015) were taken as support for the full decomposition model (Taft, 1979).

Finally, Whiting, Shtyrov, and Marslen-Wilson (2015) contrasted simple (walk), complex (swimmer), and pseudocomplex (corner) words in an MEG study. They showed that complex words differed from noncomplex words between 300 and 370 msec. At the source level, the derivational complex words differed from the noncomplex words in left middle temporal gyrus (with no difference between morphological and pseudomorphological words). The inflectional complex words differed from the noncomplex words in left middle temporal and inferior frontal gyrus (with no difference again between morphological and pseudocomplex words). The finding that morphological words did not differ from pseudomorphological words at this stage is in line with morpho-orthographic processing accounts discussed earlier.

\section{fMRI Studies}

The specificity and localization of morphological effects have also been investigated using fMRI. In a seminal study using masked priming, Devlin et al. (2004) contrasted morphological, orthographic, and semantic priming and found a reduction in activation (i.e., neural priming) within left occipitotemporal cortex for pairs sharing form (i.e., morphology and orthographic priming conditions) and a reduction in middle temporal gyrus for pairs sharing semantics (i.e., morphology and semantic priming conditions). However, activation for morphology and form primes fully overlapped in left occipitotemporal cortex and activation for morphology and semantic primes fully overlapped in left middle temporal gyrus, which was taken to suggest that the effects of morphology are not specific and can be explained by the convergence of form and meaning. However, as pointed out by Rastle and Davis (2008), all primes in the orthographic condition used in this study included affix endings (i.e., pseudocomplex word). Thus, the effect found in left occipitotemporal cortex could be explained in terms of early morpho-orthographic segmentation because the orthographic controls had morphological structure. In contrast to Devlin et al. (2004), Gold and 
Rastle (2007) found specific morphological priming effects in middle occipital gyrus in a masked priming fMRI experiment. Morphological priming was identical to pseudomorphological primes (corner-CORN) but different from either nonmorphological control primes (brothel-BROTH) or semantic primes (bucket-PAIL). Similarly, using an unmasked long-lag priming experiment, Bozic et al. (2007) reported significantly reduced activation in left frontal regions for morphologically related pairs as compared with pairs of words that shared only form or meaning. In addition, no difference was found between opaque and transparent pairs. The results were taken to suggest that left inferior frontal gyrus processes morphological structure independent of form and meaning.

\section{The Present Study}

As suggested above, the primary focus of much of the previous work has been on the nature of early morphological decomposition using the masked priming paradigm (ERPs or fMRI), which showed a somewhat limited role for semantic contributions to morphological processes. Here, we used MEG to investigate morphological, orthographic, and semantic priming with briefly presented but fully visible primes, which allows semantic or orthographic information of the primes to be processed more thoroughly (e.g., Beyersmann et al., 2014; Lavric et al., 2011; Brown \& Hagoort, 1993). We also used the same targets across all priming conditions to eliminate potential confounds due to having different targets in each condition (Feldman et al., 2015; Pastizzo \& Feldman, 2009; Feldman, 2000).

We took advantage of the excellent spatiotemporal resolution of MEG to investigate the time course and the localization of both shared and morphology-specific effects in anatomically defined ROIs that were selected according to previous MEG and fMRI findings on morphological processing (see below). As shown in Table 1, in each ROI, the global morphological priming effect (morphological vs. unrelated) was contrasted with either orthographic or semantic priming effects. The comparison between morphological and semantic priming makes it possible to assess the orthographic contribution to morphological facilitation (i.e., the $\mathrm{M}+\mathrm{O}+$ effect) because both primes are equated for overlap in meaning but only morphological primes share orthography with the target. The comparison between morphological and orthographic primes makes it possible to assess the semantic contribution to morphological facilitation (i.e., the $\mathrm{M}+\mathrm{S}+$ effect) because both primes are equated for overlap in orthography but only morphological primes share meaning with the target. In each ROI, the $\mathrm{M}+\mathrm{O}+$ and $\mathrm{M}+\mathrm{S}+$ effects were contrasted with pure orthographic or pure semantic effects to further constrain the interpretation of the joint effects between morphology and orthography or morphology and meaning.
The ROIs were as follows: (1) The left fusiform gyrus including the visual word form area involved in the recognition of visual word form (Dehaene, Le Clec, Poline, Le Bihan, \& Cohen, 2002; Cohen et al., 2000) and in the early decomposition based on morphological properties of complex words (Solomyak \& Marantz, 2010). (2) The left temporal cortex including superior (LSTG), middle (LMTG), and inferior (LITG) gyri associated with semantic processing (Price, 2012; Vartiainen et al., 2009; Bozic et al., 2007). These regions have also been shown to be involved in morphological decomposition, lexical access, and morphological recombination (Fruchter \& Marantz, 2015; Whiting et al., 2015). The LITG was further divided into three sub-ROIs corresponding to the posterior, middle, and anterior LITG. This analysis was volume-based with the constraint of having three equal volumes. In contrast to LITG, LSTG was not subdivided because of its relatively small size and small number of dipoles. (3) The left inferior frontal regions (Broca's area), which are typically associated with semantic processing and semantic unification (Price, 2012; Friederici, 2011; Hagoort, 2005; Jobard, Crivello, \& Tzourio-Mazoyer, 2003; for a review, see Binder, Desai, Graves, \& Conant, 2009) are also activated during the processing of inflectional morphemes (Whiting et al., 2015). According to the Colin27 anatomy template, the LIFG was divided into three sub-ROIs corresponding to the pars opercularis, triangularis, and orbitalis. (4) The left orbitofrontal gyrus, whose activation is associated with the effects of semantic well-formedness of morphologically complex words as indexed by the semantic coherence effect (Fruchter \& Marantz, 2015) and semantic processing of both simple sentences and more complex linguistic structures (Bemis \& Pylkkänen, 2013; Pylkkänen, Oliveri, \& Smart, 2009; Brennan \& Pylkkänen, 2008; Pylkkänen \& McElree, 2007).

\section{METHODS}

\section{Participants}

Twenty (mean age $=23.4$ years, $S D=3.18$; 9 men, 11 women) native French speaking adults took part in this study and received $€ 50$ for their participation. All participants were recruited at Aix-Marseille University (France). Because of the constraints of MEG, participants with nonremovable piercings or surgical implants were excluded. Participants with dental implants were accepted after having checked that their implants did not interfere with the MEG data acquisition during the first run. To be included in the study, participants had to (1) be monolingual native speakers of French, (2) lack any known neurological/ psychiatric disorders and report normal or corrected-tonormal hearing or vision, (3) have a nonverbal IQ within the normal range (that is, above the 25th centile on Raven's Matrices: Raven \& Court, 1995; mean $=49.05$, $S D=4.07$ ), and (4) have normal literacy skills and no previous history of learning disability. Participants were 
asked not to wear metallic or magnetic jewelry and to avoid using cosmetic products.

\section{Design and Stimuli}

The stimuli were 192 prime-target pairs selected from the LEXIQUE database (www.lexique.org/) and divided into four conditions of 48 pairs each: (1) morphologically related (ourson-OURS/bear cub-bear), (2) semantically related (peluche-OURS/plush-bear), (3) orthographically but not semantically or morphologically related (oursinOURS/urchin-bear), and (4) unrelated (gésier-OURS/ gizzard-bear). Target words were identical across all prime conditions. Prime words were presented in lower case, whereas target words were presented in upper case. All target words were monomorphemic and had a mean frequency of $58.6(S D=102.39)$ per million according to LEXIQUE, a mean length of $5.10(S D=1.07)$, and a mean number of syllable of $1.60(S D=0.76)$. Table 2 presents the main item characteristics in the four experimental conditions. In the morphological condition, all suffixed words belonged to the same morphological family. All words in the other conditions were monomorphemic (only eight words in the orthographic condition were pseudoderived). Across the four conditions, the primes were matched in terms of frequency (all $p s>.30$ ), number of letters (all $p s>.30$ ), and number of syllables (all $p s>$ .30). To control for the semantic similarity between the morphological and the semantic condition, we calculated the cosine similarity between prime and target using latent semantic analysis (lsa.colorado.edu/). There was no difference $(p>$.63) in semantic association strength between the morphological $(M=0.28 ; S D=0.18)$ and the semantic condition $(M=0.24 ; S D=0.17)$. Concerning the orthographic overlap, there was no difference $(p>$ .34) between both morphological and orthographic conditions. In the morphological condition, targets and primes shared on average the first 3.7 letters $(S D=1.07)$, and in the orthographic condition, they shared on average the first 3.5 letters $(S D=0.85)$.

For the purpose of the lexical decision task (LDT), we created 48 pseudoword targets by changing two letters from each target word (e.g., OURS $\rightarrow$ OIRT). The pseudo- word targets were preceded by 192 word primes, which were selected to match the primes in the word condition in terms of frequency $(M=9.8 ; S D=2.89)$, number of letters $(M=6.9 ; S D=0.29)$, and number of syllables $(M=2 ; S D=0.0)$. There was no orthographic or morphological overlap between the pseudoword targets and the word primes.

All items were divided into four lists. Each list contained 48 word targets ( 12 by condition) and 48 pseudoword targets. Lists were created such that each target word or pseudoword would appear only once in each list. The order of trials in each list was pseudorandom with a maximum of two repetitions of the same condition. Each participant saw the four lists in a counterbalanced order of presentation, using a Latin square design. The practice session consisted of 10 trials.

\section{Experimental Procedure}

We used Presentation (Neurobehavioral Systems, Berkeley, CA; neurobs.com/) for stimulus presentation. MEG signals were recorded while the participant was lying in a horizontal position to reduce the participant's movements. The stimuli were projected using a video projection onto a screen that was located $\sim 42 \mathrm{~cm}$ away from the participant. The stimuli were displayed in black 16-point Courier New. To limit eye movements, stimuli had maximal width of $2.24^{\circ}$ and maximal height of $0.41^{\circ}$. Each trial consisted of a fixation cross appearing in the center of the screen for $500 \mathrm{msec}$, followed by a blank for $50 \mathrm{msec}$ and a prime for $200 \mathrm{msec}$. The target word was presented $50 \mathrm{msec}$ after the offset of the prime (stimulus onset asynchrony $=$ $250 \mathrm{msec}$ ) and remained on the screen until the participant's response. The participant's responses were registered using a LUMItouch optical response keypad with five keys (each corresponding to a right hand finger). Participants were instructed to press the button with the right index finger when the target was a word and with the right thumb when the target was not a word. The intertrial interval was $1900 \mathrm{msec}$. Participants were instructed to move as little as possible. Finally, participants were asked to eye-blink after their response, but not during the trial.

Table 2. Characteristics of the Primes in the Four Experimental Conditions

\begin{tabular}{lcccc}
\hline & \multicolumn{3}{c}{ Type of Priming } \\
\cline { 2 - 5 } & $\begin{array}{c}\text { Morphological } \\
\text { Ourson-OURS } \\
\text { (bear cub-bear) }\end{array}$ & $\begin{array}{c}\text { Orthographic } \\
\text { oursin-OURS } \\
\text { (urchin-bear) }\end{array}$ & $\begin{array}{c}\text { Semantic } \\
\text { peluche-OURS } \\
\text { (plush-bear) }\end{array}$ & $\begin{array}{c}\text { Unrelated } \\
\text { gézier-OURS } \\
(\text { gizzard-bear) }\end{array}$ \\
\hline Frequency & $9.52(15.51)$ & $10.09(12.38)$ & $12.33(11.81)$ & $9.53(7.43)$ \\
Number of letters & $6.84(1.12)$ & $6.85(1.07)$ & $6.60(1.74)$ & $6.61(0.92)$ \\
Number of syllables & $2.16(0.37)$ & $2.06(0.52)$ & $2.17(0.74)$ & $2.12(0.33)$ \\
\hline
\end{tabular}




\section{MEG Data Acquisition}

Continuous MEG of spontaneous cerebral activity was recorded in a magnetically shielded room using a whole head, 248-channel biomagnetometer system (4D Neuroimaging, San Diego, CA). The sampling rate was $2034.5 \mathrm{~Hz}$. We followed the guidance provided by Gross et al. (2013) for data acquisition. EOG and EKG were recorded. To determine the location of the head with respect to the MEG array, five coils were fixed on the participant's head. These coils as well as the surface of the head were digitized with a 3-D digitizer (Polhemus Fastrack, Polhemus Corporation, Colchester, VT), and the head position was measured at the beginning and end of each run. The head shape obtained from the digitization of the head was used to check and possibly compensate for differences in head position between runs.

\section{MEG Analysis and Statistical Methodology}

Data preprocessing was performed using Anywave software (meg.univ-amu.fr/wiki/Anywave; Colombet, Woodman, Bénar, \& Badier, 2015) for visual rejection of channels showing excessive noise, muscle, or SQUID jump artifacts and Fieltrip Matlab 8.1 toolbox (fieldtrip.fcdonders.nl/; Oostenveld, Fries, Maris, \& Schoffelen, 2011) for filtering, baseline correction, independent component analysis, epoching, trial rejection, and averaging. The preprocessing and source reconstruction were performed independently for each participant. Data were filtered by a band-pass filter in the range of $0.5-300 \mathrm{~Hz}$ (Butterworth IIR filter, secondorder filter, and zero-phase forward and reverse filter). We applied independent component analysis (runica, learning rate $0.1 \%$; EEGlab implementation, 231 components) on continuous data to identify and remove the heartbeat and blink artifacts. For epoching, event-related fields were time-locked to stimulus onset and epoch was comprised between -500 and $1000 \mathrm{msec}$ with respect to target stimulus onset. Sensor averaging was computed for each participant and represented the mean time course per channel over epochs of the same experimental condition (morphological, orthographic, semantic, unrelated, and pseudoword). Trial rejection was performed manually, and only correct trials were retained for data analysis.

The source reconstruction trials were filtered applying a low-pass filter with a cutoff frequency of $25 \mathrm{~Hz}$ and resampled to $200 \mathrm{~Hz}$. The source level analyses were carried out following the beamforming methodology using the Fieldtrip toolbox. The head shape of each participant was coregistered to that of the MNI Colin27 anatomy template (Holme et al., 1998), which was modified to fit each participant's digitized head shape using SPM8 (Wellcome Department of Imaging Neuroscience, University College London, www.fil.ion.ucl.ac.uk). To determine the most likely distribution of neural activity, the inverse problem was computed from the forward solution. For that purpose, a single shell brain model was built based on the modified template (Harpaz, Lavidor, \& Goldstein, 2013), and a 3-D grid with 10-mm spacing dipoles was defined in the inner skull volume, resulting in 2127 dipoles. Thereafter, the linear constrained minimum variance beamformer was applied to quantify the time course of the neuronal activity generated by these dipoles, utilizing a free orientation for the source estimates and a regularization parameter fixed at 5\%. To correct for the bias induced by the noise, we calculated $Z$ scores for the 1000 msec posttarget stimulus onset against the baseline period -500 to $-300 \mathrm{msec}$ preprime stimulus. Finally, to correct for potential baseline differences before the onset of the target, we subtracted the mean value of the normalized signal in the pre-target interval -250 to $0 \mathrm{msec}$ from the normalized source signal of each generator.

For the anatomical ROI analysis, we referred to the Automated Anatomical Labeling atlas (Tzourio-Mazoyer et al., 2002) in Colin27 space including 116 brain areas in which each dipole was associated with the corresponding ROI, and the averaging of corrected sources was then performed by ROI and by participant. Finally, we computed paired $t$ tests as a statistical analysis, and the resulting $t$ values were corrected for multiple comparisons over the time period 0-650 msec posttarget stimulus onset. The technique that we used for multiple comparison correction corresponds to the cluster-based permutation method proposed by Maris and Oostenveld (2007). Specifically, this statistical test was performed by computing a $p$ value under the permutation distribution and comparing it with some critical $\alpha$ level. The procedure consisted of performing a nonparametrical permutation test on each time point between two experimental conditions during the whole time period of 0-650 $\mathrm{msec}$. The $p$ values resulting for each cluster (i.e., the maximum cluster level statistic) was compared with the results of the same procedure repeated on 10,000 random permutations.

\section{RESULTS}

\section{Behavioral Results}

Table 3 presents the RTs and the error rates (\%) for the four conditions. We ran repeated-measures ANOVAs on the RT data for correct responses and for error rates, with Prime condition (morphological, orthographic, semantic, and unrelated) as a within-subject factor. After removing extreme values (RTs > $4000 \mathrm{msec}$, less than $0.1 \%$ ), the ANOVA on RTs yielded a significant effect of Prime condition, $F(3,57)=13.23, p=.002, \eta^{2}=0.347$. We conducted a set of pairwise comparisons, correcting the level of significance of each test using the false discovery rate, a practical and powerful approach to multiple testing developed by Benjamini and Hochberg (1995). The comparisons indicated a significant effect of morphological priming $(p<.001$; less than the Benjamini-Hochberg [BH] threshold $q=0.008)$ and a significant effect of semantic priming $(p=.02$; less than the $\mathrm{BH}$-corrected 
Table 3. Mean RTs (in msec) and Percent Errors for Each Prime Condition

\begin{tabular}{lccc}
\hline Prime Condition & $\begin{array}{c}\text { RTs } \\
(\mathrm{msec})\end{array}$ & Main Effects & $\begin{array}{c}\text { Error Rates } \\
(\%)\end{array}$ \\
\hline Morphological & $646(155)$ & $-67 \mathrm{msec}^{* * *}$ & $1.04(1.21)$ \\
Orthographic & $692(169)$ & $-21 \mathrm{msec}$ & $1.24(1.76)$ \\
Semantic & $673(152)$ & $-40 \mathrm{msec}^{*}$ & $1.35(1.86)$ \\
Unrelated & $713(195)$ & & $2.08(2.82)$ \\
Pseudowords & $766(192)$ & & $1.65(1.52)$ \\
\hline
\end{tabular}

Standard deviations in parentheses.

$* p<.05$.

$* * * p<.001$

threshold $q=0.03)$, but no significant effect of orthographic priming $(p=.169$; greater than the $\mathrm{BH}$-corrected threshold $q=0.05)$. In addition, there was a significant difference between the morphological and the orthographic priming condition $(p<.001$; less than the $\mathrm{BH}$ corrected threshold $q=0.01$ ). There was also a significant difference between the orthographic and semantic prim- ing condition $(p<.05$; less than the $\mathrm{BH}$-corrected threshold $q=0.04)$. Finally, there was a significant difference between the morphological and semantic priming condition $(p<.01$; less than the BH-corrected threshold $q=0.02)$. On the error data, the ANOVA revealed no significant effect of Prime condition, $F(3,57)=1.93, p=.13$, and none of our multiple tests yielded significant results with BH-corrected thresholds.

\section{MEG Results}

For each ROI, we conducted five critical contrasts to assess: (1) the global morphological effect (morphological vs. unrelated), (2) the $\mathrm{M}+\mathrm{S}+$ effect (morphological vs. orthographic), (3) the $\mathrm{M}+\mathrm{O}+$ effect (morphological vs. semantic), (4) the pure orthographic effect (orthographic vs. unrelated), and (5) the pure semantic effect (semantic vs. unrelated). For each contrast and ROI, we ran paired $t$ tests at each time point over the time window of interest 0-650 msec, and all thresholds were corrected for multiple comparison using the method of Maris and Oostenveld (2007). The results for each ROI are presented below. Note that two ROIs, the left fusiform and left middle temporal gyri, showed no significant results for any of the contrasts.

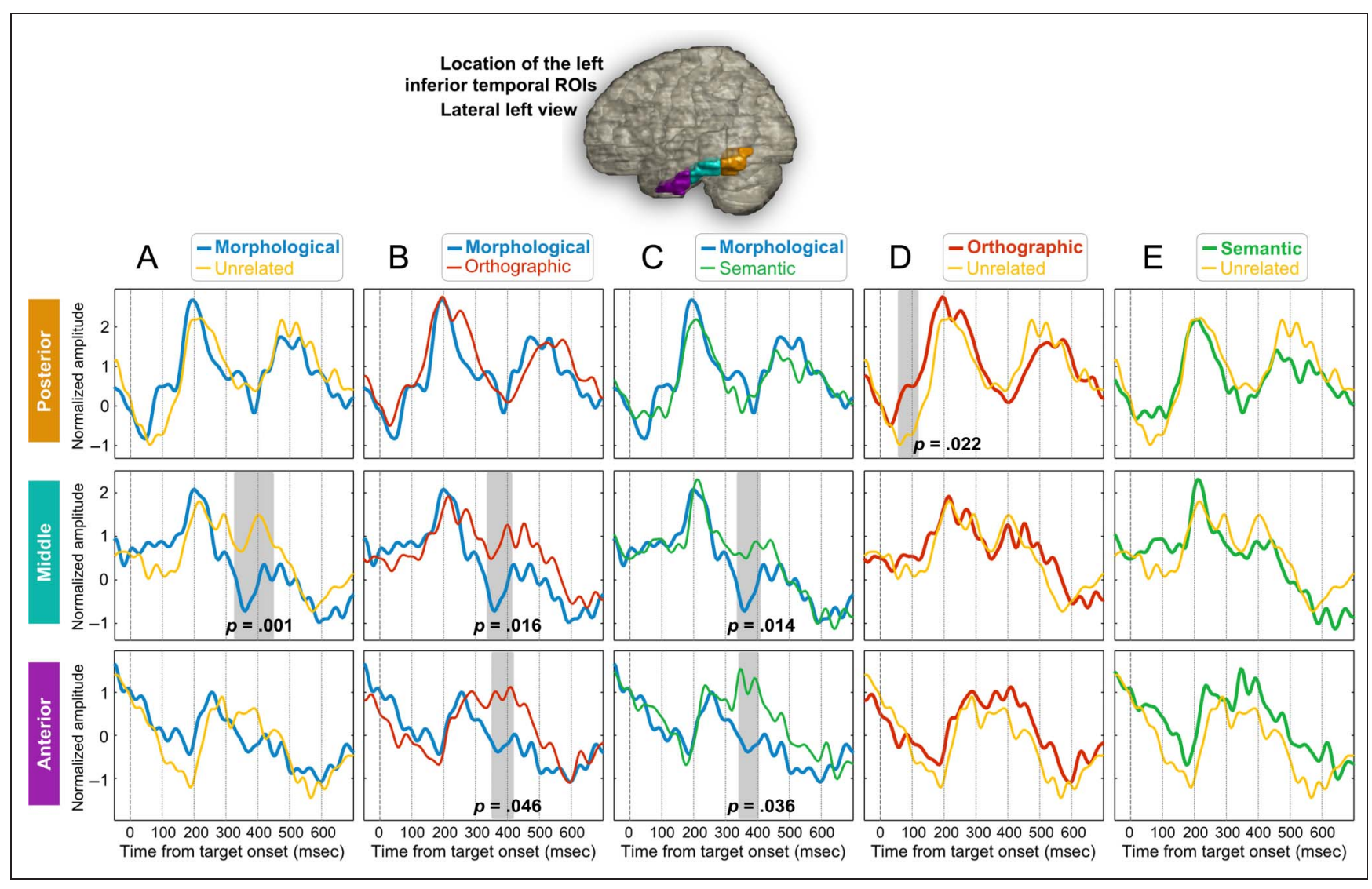

Figure 1. Mean source signal activity in the left inferior temporal ROI. (A) Global morphological priming $M+$, (B) $M+S+$ effect, $(C) M+O+$ effect, (D) pure orthographic priming effect $\mathrm{O}+$, and (E) pure semantic priming effect $\mathrm{S}+$. The significant time windows after correction for multiple comparisons are shaded in gray. 


\section{Left Inferior Temporal ROI}

Figure 1 presents the time course of average activations for the posterior, middle, and anterior part of the left inferior temporal ROI.

In posterior LITG, results revealed significant differences only for the pure orthographic effect ( $p=.02$ for the cluster at 55-120 msec; see Figure 1D, posterior). The present orthographic priming effect was indeed due to a reduction of the absolute activity ${ }^{1}$ for the condition of interest (i.e., neural priming), because the activity of the orthographic condition was lower (mean absolute value $=$ $0.4 \pm 1.2$ ) than that of the unrelated condition (mean absolute value $=0.7 \pm 1.7$ ). None of the other contrasts revealed significant effects in posterior LITG.

In the middle LITG, we found a global morphological priming effect in the time window of the M350 (325450 msec, $p=.001$; see Figure 1A, middle). As before, this effect was due to a reduced activity of the morphological condition (mean $=0.1 \pm 1.3$ ) compared with the unrelated condition (mean $=1.0 \pm 1.3$ ). In approximately the same time window, we found a significant $\mathrm{M}+$ $\mathrm{S}+$ effect $(p=.01$ for the cluster at 335-415 msec; Figure $1 \mathrm{~B}$, middle), for which the absolute activity of the morphological condition was lower (mean $=0.01 \pm 0.9)$ than that of the orthographic condition (mean $=0.8 \pm$ $0.9)$, and a significant $\mathrm{M}+\mathrm{O}+$ effect ( $p=.01$ for the cluster at 335-410 msec; Figure $1 \mathrm{C}$, middle), for which the activity of the morphological condition was also lower (mean = $0.3 \pm 1.4$ ) than that of the semantic condition (mean $=0.7 \pm$ 1.7). There were no significant effects of pure orthographic (Figure 1D, middle) or pure semantic priming (Figure 1E, middle).

In the anterior LITG, no global morphological priming effect was found. However, we found a significant $\mathrm{M}+\mathrm{S}+$ effect ( $p=.04$ for the cluster at 350-420 msec; Figure 1B, anterior) and a significant $\mathrm{M}+\mathrm{O}+$ effect $(p=.03$ for the cluster at [340-405] msec; Figure 1C, anterior). These effects were due to reduced activity of the morphological condition (mean $=0.2 \pm 2.5$ ) compared with the orthographic condition (mean $=0.9 \pm 1.7$ ) or the semantic condition $($ mean $=1.2 \pm 2.5$ ). There were no significant effects of pure orthographic (Figure 1D, anterior) or pure semantic priming (Figure 1E, anterior).

\section{Left Superior Temporal ROI}

Figure 2 displays the time course of average activation in left superior temporal ROI. Results showed no significant global morphological priming effect (Figure 2A). However, we found a significant $\mathrm{M}+\mathrm{S}+$ effect in the time window of the M250 ( $p=.01$ for the cluster at 240$300 \mathrm{msec}$ ). The $\mathrm{M}+\mathrm{S}+$ effect reflected reduced activity in the morphological condition (mean $=0.1 \pm 1.1$ ) compared with the orthographic condition (mean $=0.7 \pm$ 1.1). Moreover, there was a significant $M+S+$ effect in a later time window that started at $\sim 580 \mathrm{msec}$ posttarget

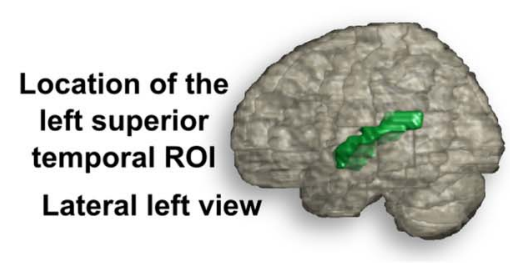

Mean source signal in the left superior temporal ROI (22 dipoles, 20 subjects)

A

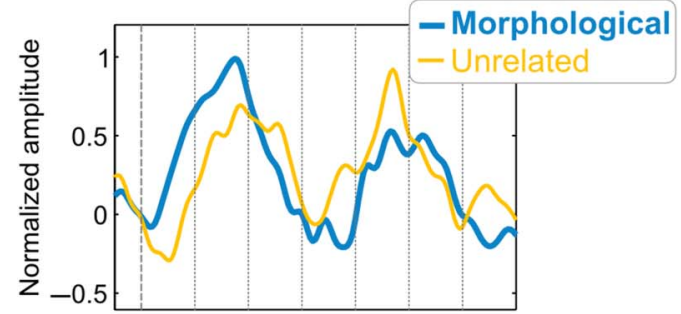

$\mathrm{B}$

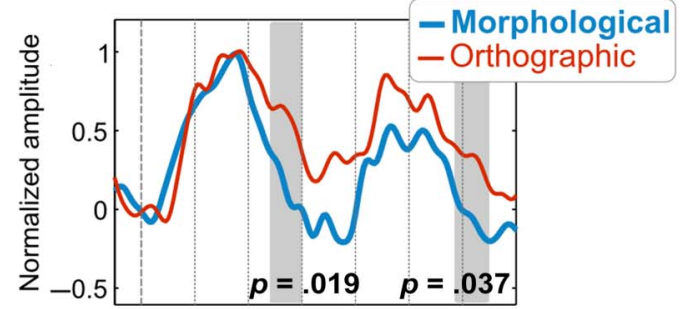

C

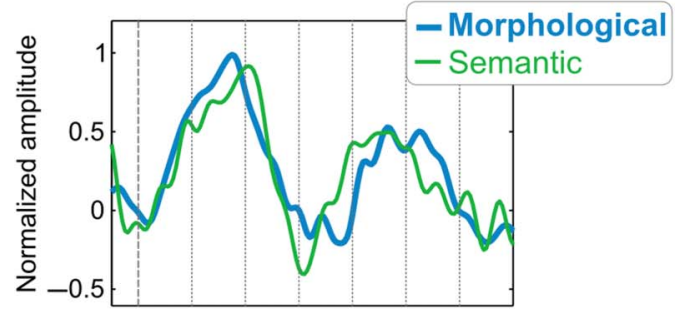

D

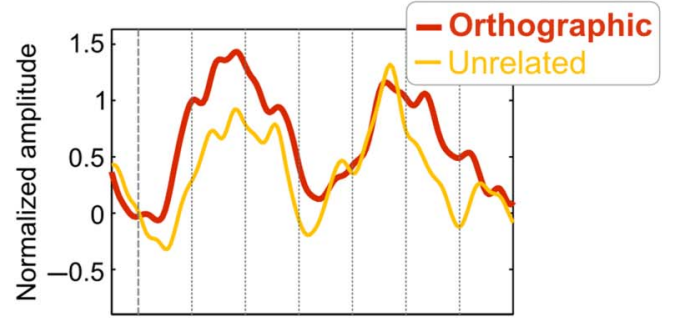

$\mathrm{E}$

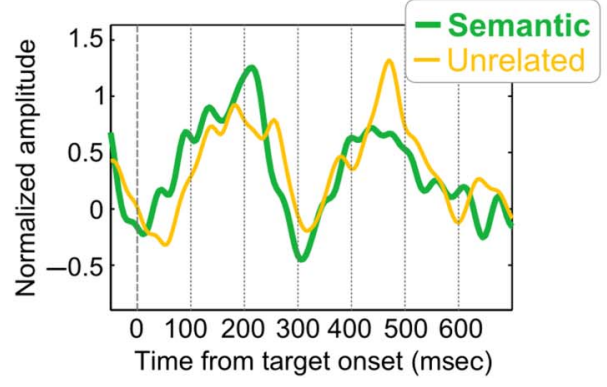

Figure 2. Mean source signal activity in the left superior temporal ROI. (A) Global morphological priming $\mathrm{M}+$, (B) $\mathrm{M}+\mathrm{S}+$ effect, (C) $\mathrm{M}+\mathrm{O}+$ effect, (D) pure orthographic priming effect $\mathrm{O}+$, and (E) pure semantic priming effect $\mathrm{S}+$. The significant time windows after correction for multiple comparisons are shaded in gray. 
onset ( $p=.03$ for the cluster at $585-650 \mathrm{msec}$ ), which again reflected reduced activity of the morphological condition $($ mean $=0.2 \pm 1.1$ ) compared with the orthographic condition (mean $=0.5 \pm 1.2$ ). The $\mathrm{M}+\mathrm{O}+$ effect was not significant (Figure 2C), and there were no effects of pure orthographic (Figure 2D) and pure semantic priming (Figure 2E).

\section{Left Inferior Frontal ROI}

Figure 3 displays the time course of average activation in left inferior frontal ROI. We conducted analyses on the three left inferior frontal sub-ROIs including pars opercularis, triangularis, and orbitalis. The results were significant only in pars orbitalis and revealed a significant global morphological priming effect $(p=.007$ for the cluster at 350-460 msec; Figure 3A), which was due to a reduction of activity for the morphological condition (mean $=0.4 \pm 1.7$ ) compared with the unrelated condition $($ mean $=0.8 \pm 1.5$ ). The $\mathrm{M}+\mathrm{S}+$ effect was significant between 440 and $495 \mathrm{msec}(p=.04$; Figure 3B) and the activity of the morphological condition was lower (mean $=0.3 \pm 1.4)$ than that of the orthographic condition (mean $=0.6 \pm 1.8)$. The $\mathrm{M}+\mathrm{O}+$ effect was also significant between 345 and $420 \mathrm{msec}(p=.01$; Figure 3C) and the activity of the morphological condition was again lower (mean $=0.4 \pm 1.8$ ) than that of the semantic condition (mean $=0.8 \pm 1.6$ ). The timing of these effects is consistent with the time window of the M350. No significant effects were obtained for pure orthographic (Figure 3D) and pure semantic priming (Figure 3E).

\section{Left Orbitofrontal ROI}

In the left orbitofrontal ROI, results showed a significant global morphological priming effect in the M350 time window ( $p=.0004$ for the cluster at 320-465 msec; Figure $4 \mathrm{~A}$ ). As before, this effect was due to a reduced activity of the morphological condition (mean $=0.4 \pm$ 1.3) compared with the unrelated condition (mean $=$ $0.7 \pm 1.3$ ). Moreover, there was a significant $\mathrm{M}+\mathrm{S}+$ effect in a somewhat smaller and later time window $(p=.01$ for the cluster at 435-500 msec; Figure 4B), for which the activity of the morphological condition was lower (mean = $0.3 \pm 1.2$ ) than that of the orthographic condition (mean $=$ $0.6 \pm 2.3$ ). The $\mathrm{M}+\mathrm{O}+$ was not significant (Figure $4 \mathrm{C}$ ), and there were no effects of pure orthographic (Figure 4D) and pure semantic priming (Figure 4E).

\section{DISCUSSION}

The behavioral results showed a significant effect of morphological and semantic priming but no effect of orthographic priming. Moreover, the contrast analyses revealed that there was a significant difference between morphological and orthographic priming $(\mathrm{M}+\mathrm{S}+$ effect $)$ and between morphological and semantic priming $(\mathrm{M}+\mathrm{O}+$
Location of the left inferior frontal pars orbitalis ROI

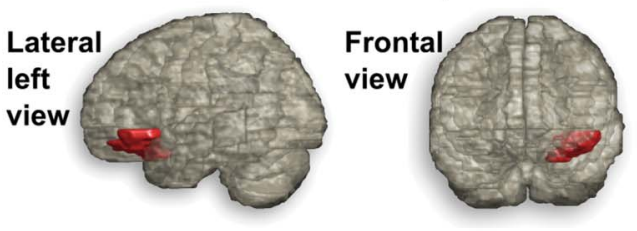

Mean source signal in the left inferior frontal ROI (14 dipoles, 20 subjects)

A

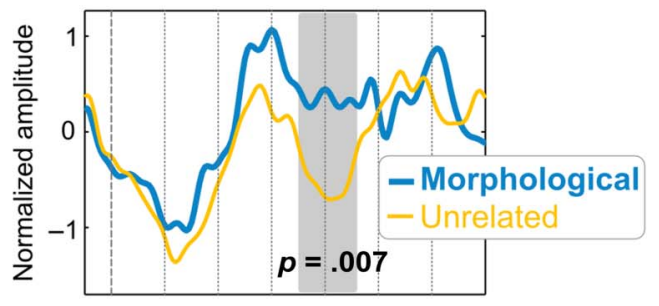

B

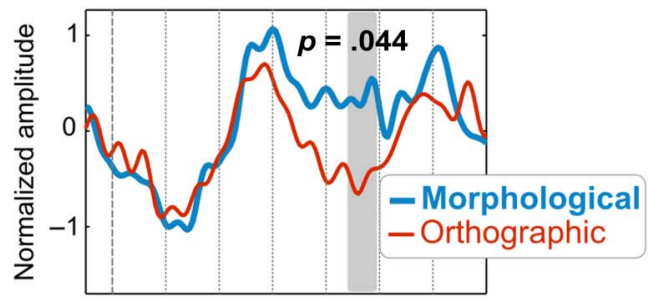

C

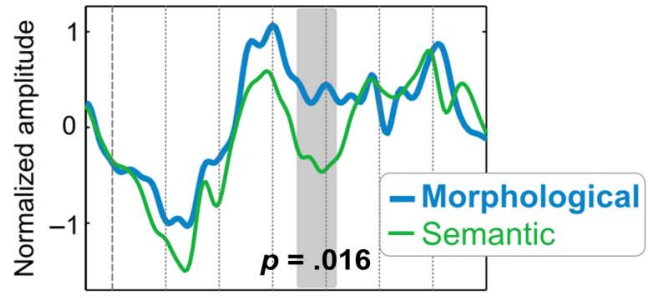

D

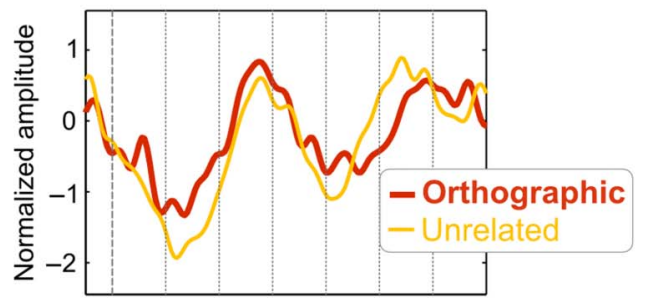

$\mathrm{E}$

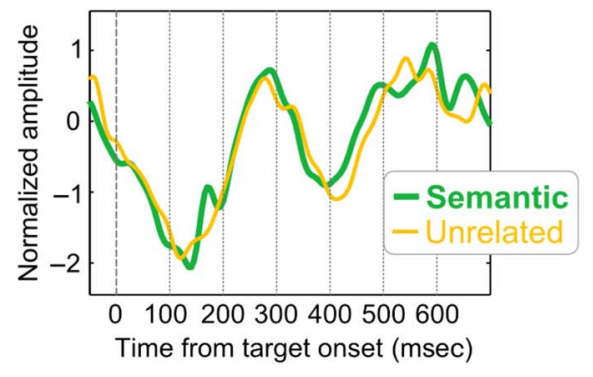

Figure 3. Mean source signal activity in the left inferior frontal ROI, only the pars orbitalis has been plotted. (A) Global morphological priming $\mathrm{M}+$, (B) $\mathrm{M}+\mathrm{S}+$ effect, (C) $\mathrm{M}+\mathrm{O}+$ effect, (D) pure orthographic priming effect $\mathrm{O}+$, and $(\mathrm{E})$ pure semantic priming effect $\mathrm{S}+$. The significant time windows after correction for multiple comparisons are shaded in gray. 


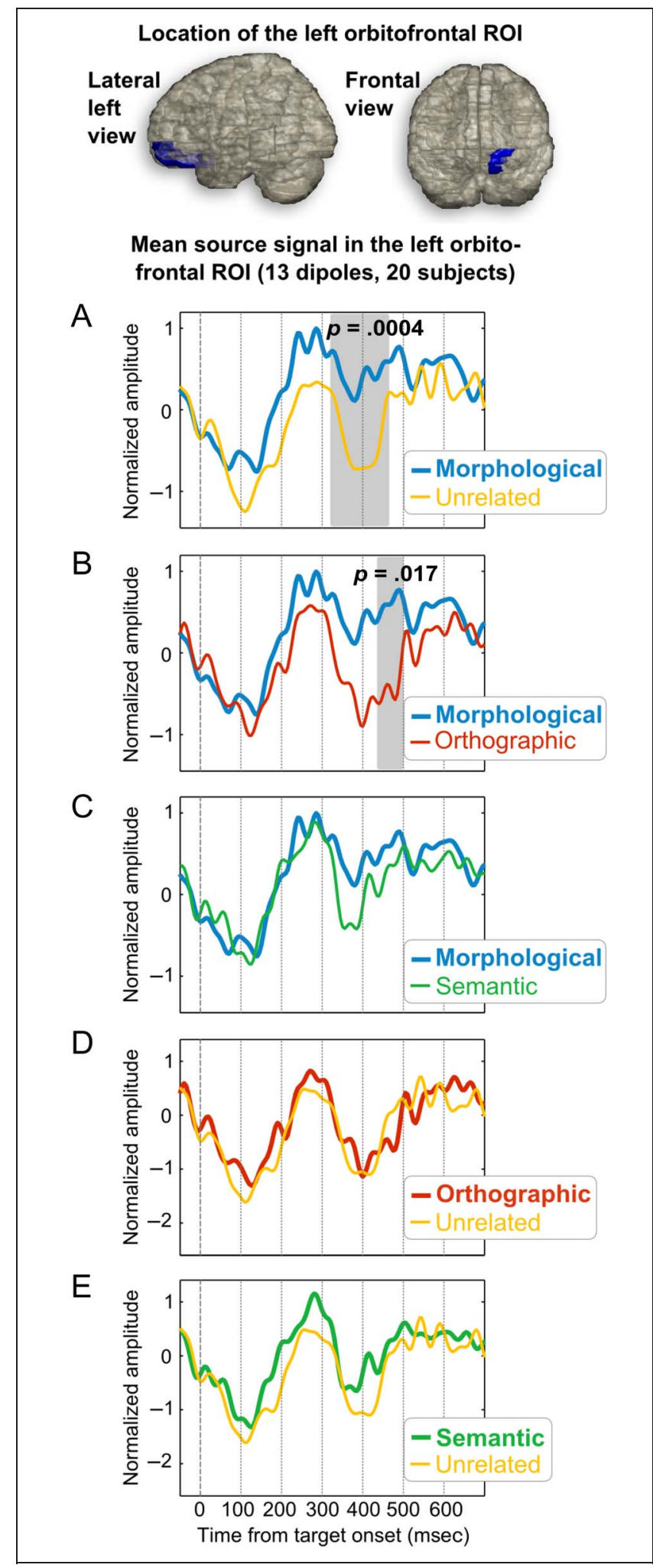

Figure 4. Mean source signal activity in the left orbitofrontal ROI. (A) Global morphological priming $\mathrm{M}+$, (B) $\mathrm{M}+\mathrm{S}+$ effect, (C) $\mathrm{M}+\mathrm{O}+$ effect, (D) pure orthographic priming effect $\mathrm{O}+$, and (E) pure semantic priming effect $\mathrm{S}+$. The significant time windows after correction for multiple comparisons are shaded in gray. effect). The magnitude of morphological priming was greater than the magnitude of semantic priming. These results are consistent with those of Beyersmann et al. (2014) and confirm that morphological priming cannot be explained by semantic or form overlap alone. MEG for the five critical contrasts was analyzed in the brain regions that have been associated with morphological, morpho-orthographic, and morphosemantic processing. Below, we will discuss the effects for each ROI.

\section{Left Inferior Temporal ROI}

In the posterior left inferior temporal ROIs, the results showed a priming effect at $\sim 100 \mathrm{msec}$ in the pure orthographic condition, which most likely reflects shared orthography between prime and target compared with an unrelated condition. An almost identical effect was found in the pure morphological condition, although it failed to reach significance. Such an effect was expected because primes and targets in the morphological condition share orthography. Consistent with the idea that the left inferior temporal gyrus in this early time window responds primarily to basic orthographic information, we did not see any early effect in this region when morphological primes were contrasted with orthographic primes (both share orthography) or when semantic primes were contrasted with unrelated primes (none shares orthography).

Thus, the present pattern suggests that the early M130 response is only associated with orthographic processing (Dehaene et al., 2002; Cohen et al., 2000). Note that the M130 orthographic effect was localized in posterior LITG rather than left fusiform gyrus, for which no significant effects were found. However, in our source-space model, LITG is actually situated in the prolongation of left fusiform gyrus. Given the hierarchical organization of visual word processing along the ventral route (posterior-toanterior gradient reflecting more integrated word processing in anterior parts of the ventral stream; see Vinckier et al., 2007), it is safe to assume that the present posterior LITG activation reflects basic orthographic processing of the visual word form area.

Upon examination of the middle left inferior temporal ROI, our results showed a global morphological priming effect during the time window of the M350 (Figure 1A, middle). Crucially, in the same time window, morphological priming was significant when either orthographic or semantic overlap was partialed out $(\mathrm{M}+\mathrm{S}+$ and $\mathrm{M}+\mathrm{O}+$ effects), suggesting that the effect reflects both semantic and orthographic contributions to morphological facilitation. Given that we did not find pure effects of either orthographic or semantic overlap in this time window, it can be argued that the $\mathrm{M}+\mathrm{S}+$ effect cannot be explained by pure semantic overlap and that the $\mathrm{M}+\mathrm{O}+$ effect cannot be explained by pure orthographic overlap.

The results in the anterior left inferior temporal ROI mirrored those obtained in middle left inferior temporal ROI with significant $\mathrm{M}+\mathrm{S}+$ (Figure $1 \mathrm{~B}$, anterior) and $\mathrm{M}+\mathrm{O}+$ 
effects (Figure 1C, anterior) effects. However, our analyses failed to show a global morphological priming effect in anterior LITG. This pattern suggests that semantic and orthographic competitors tend to produce inhibition in the anterior part of LITG compared with unrelated primes, which leads to stronger effects in the $\mathrm{M}+\mathrm{S}+$ and the $\mathrm{M}+\mathrm{O}+$ contrasts as compared with the pure morphological contrast (morphology vs. unrelated).

In summary, along the ventral route in the time window of the M350, we found both $\mathrm{M}+\mathrm{S}+$ and $\mathrm{M}+\mathrm{O}+$ effects in the middle and anterior LITG. The effects were morphology specific as they remained significant when either orthographic or semantic overlap was controlled for and these areas did not respond to pure orthographic or pure semantic overlap. In line with dual-route models of reading aloud (Coltheart, Rastle, Perry, Langdon, \& Ziegler, 2001), the ventral (direct) route is in charge of mapping form onto meaning (for a meta-analysis, see Jobard et al., 2003). Our results suggest that pure orthographic processes seem to occur in the posterior part and that morphological processing takes place as one moves along the ventral route from posterior to anterior parts of LITG, as predicted by Dehaene et al.'s hierarchical model of word recognition (Dehaene, Cohen, Sigman, \& Vinckier, 2005). Although we cannot interpret the $\mathrm{M}+\mathrm{S}+$ and $\mathrm{M}+\mathrm{O}+$ effects as pure "morphosemantic" and pure "morphoorthographic" effects, it seems nevertheless the case that semantic and orthographic contributions to morphological facilitation might occur at the same time along the ventral route.

\section{Left Superior Temporal ROI}

Upon examination of the left superior temporal ROI, results revealed a significant $\mathrm{M}+\mathrm{S}+$ effect in the time window of the M250 and during a later time window $(\sim 585-650 \mathrm{msec})$. Thus, in this region, the morphology effect survived when orthographic overlap was partialed out, suggesting that the left superior temporal gyrus is in charge of the semantic "part" of the morphological priming effect. Yet, the effect is morphology specific because pure semantic overlap did not yield a significant effect in this ROI (Figure 4E). Interestingly, we did not find a significant $\mathrm{M}+\mathrm{O}+$ or a pure orthographic effect in this area. Thus, the dissociation between the nonsignificant $\mathrm{M}+\mathrm{O}+$ effect and the significant $\mathrm{M}+\mathrm{S}+$ effect suggests that the left superior temporal gyrus might analyze the morphemes in terms of their semantic overlap with the target word rather than in terms of their orthographic overlap. However, we fully acknowledge that the lack of pseudocomplex words (e.g., corner) in this study makes it difficult to clearly interpret this effect as purely "morphosemantic" because the morphological condition contains two key features that are absent in the orthographic condition: semantic overlap as well as a suffix. The use of a pseudocomplex condition would have allowed us to test more directly whether this effect is truly morphosemantic or whether it is due to the presence of a suffix. Although this remains a fundamental limitation of this study, the presence of a morphosemantic priming effect in LSTG is consistent with previous studies that found effects of derivational family entropy (i.e., a measure associated with lexical access for the decomposed morphemes and an index of stem lookup) in LSTG and LMTG during the time window of the M250 (Fruchter \& Marantz, 2015). Moreover, previous MEG studies have associated activation of the left superior temporal gyrus with lexical and semantic analyses (Vartiainen et al., 2009; Pylkkänen \& McElree, 2007; Helenius, Salmelin, Service, \& Connolly, 1998).

\section{Left Inferior Frontal ROI}

Upon examination of the left inferior frontal ROI, the results showed a global morphological priming effect between 350 and $460 \mathrm{msec}$. This global effect can be broken down into two separate components. The early part seems to be due to a $\mathrm{M}+\mathrm{O}+$ effect that occurs during the 345 $420 \mathrm{msec}$ time window (Figure 3C) and the later part to a $\mathrm{M}+\mathrm{S}+$ effect that occurs in the 440-495 msec time window (Figure 3B). Note that this is the only area where we found a sequential order of $\mathrm{M}+\mathrm{O}+$ and $\mathrm{M}+\mathrm{S}+$ effects. As in the other ROIs, the morphological effect could not be explained by pure orthographic or semantic overlap because the pure effects yielded no significant differences in this ROI.

The left inferior frontal gyrus has been associated with morphological processing in previous fMRI studies (Bozic et al., 2007; Davis, Meunier, \& Marslen-Wilson, 2004). Moreover, Whiting et al. (2015) reported effects of inflectional morphology in LIFG in precisely the same time window (M350). Our results add to these findings by showing that the LIFG is probably sensitive to both orthographic and semantic contributions to morphological priming. Indeed, the LIFG is well known to be activated in a variety of semantic tasks, such as selecting and retrieving related semantic attributes and semantic concept of words (Price, 2012) or retrieval of semantic information from long-term memory (Noppeney \& Price, 2003; Adams \& Janata, 2002; Wagner, Koutstaal, Maril, Schacter, \& Buckner, 2000). However, it is also activated by orthographic tasks that require precise lexical orthographic processing (Cornelissen et al., 2009), such as making lexical orthographic choices between phonologically identical words (Montant, Schön, Anton, \& Ziegler, 2011).

\section{Left Orbitofrontal ROI}

Upon examination of the left orbitofrontal ROI, results showed a global morphological priming effect during the time window of the M350 (Figure 4A). Morphological priming was significant when orthographic overlap was controlled for $(\mathrm{M}+\mathrm{S}+$ effect), as shown by the significant contrast between the morphological and orthographic conditions (Figure 4B) in a late M350 time window 
(435-500 msec), suggesting that the effect taps the semantic contribution to morphological facilitation. Again, pure semantic priming was not significant (Figure 4E), showing that the morphological effect could not be explained by semantic overlap alone. By contrast, the orthographic contribution to morphological priming and the pure orthographic priming effect were not significant in left orbitofrontal ROI, suggesting that this region is specifically involved in morphological processing during a semantically driven morphological recombination stage, where morphemic units are recombined to recognize the whole word. Previous MEG studies have indeed shown that left medial orbitofrontal regions were involved in semantic composition (Fruchter \& Marantz, 2015; Pylkkänen et al., 2009; Brennan \& Pylkkänen, 2008; Pylkkänen \& McElree, 2007). Moreover, Fruchter and Marantz (2015) showed that semantic coherence, a statistical measure used to quantify the gradient semantic well-formedness of complex words, had an effect in left orbitofrontal cortex in the $\sim 350-500$ msec time window.

\section{Summary and Conclusions}

The main significant MEG results from this study are summarized in Figure 5, which presents a hypothetical model of morphological processing. According to this model, the posterior LITG performs an initial orthographic analysis as revealed by the early M130 response. Although we did not find significant early effects of morphoorthographic segmentation, it can be assumed that early morpho-orthographic segmentation is likely to take place in the posterior LITG around $170 \mathrm{msec}$ as indicated by previous MEG results that specifically investigated these effects (Solomyak \& Marantz, 2010). Hypothetically, the activation is sent along the ventral and dorsal route. At $250 \mathrm{msec}$, the LSTG might analyze the morphological structure with respect to the semantic overlap and passes activation on to frontal areas only if a morphologically complex prime shares meaning with the target. Form primes might be recognized as orthographic competitors and create inhibition in LSTG. Along the ventral route, lexical access of morphemes might occur in the middle and anterior LITG around $350 \mathrm{msec}$, as revealed by the M350. The activation is specific to morphemes, neither form nor meaning alone produce similar effects. The activation is passed on onto frontal areas, which might be in charge of morphological recombination (Fruchter \& Marantz, 2015) and semantic unification (Hagoort, 2005). This seems to take place in LIFG and left orbitofrontal gyrus, as revealed by the late M350 response.

Several conclusions can be drawn from these results. First, morphological effects were not localized in one specific area but distributed over a vast network that involved left inferior temporal gyrus, left superior temporal gyrus, left inferior frontal gyrus, and left orbitofrontal gyrus. Second, all morphological effects were specific, that is, in none of the ROIs could morphology effects be explained by pure orthographic or pure semantic overlap. This finding strongly contradicts previous claims according to which morphological processing is simply the sum of orthographic and semantic processes (Devlin et al., 2004). Third, we found evidence that the ventral route was sensitive to both the orthographic and semantic "part" of the morphological priming effect. Although we cannot interpret our $\mathrm{M}+\mathrm{O}+$ and $\mathrm{M}+\mathrm{S}+$ effects in terms of pure "morpho-orthographic" versus pure
Figure 5. Hypothetical brain network of morphological processing. (1) The posterior LITG performs and initial orthographic analysis as revealed by the early M130 response. (2) The LSTG then analyses the morphological structure with respect to the semantic overlap at $250 \mathrm{msec}$. (3) The middle and anterior LITG carry out orthographic and semantic access of morphemes, as revealed by the M350.

(4) Frontal areas integrate form- and meaning-based representations ( $4 \mathrm{a}$ and $4 \mathrm{~b}$ ). Recombination (Fruchter \& Marantz, 2015) and semantic unification (Hagoort, 2005) might take place in LIFG and left orbitofrontal gyrus (5), as revealed by the late M350 responses.

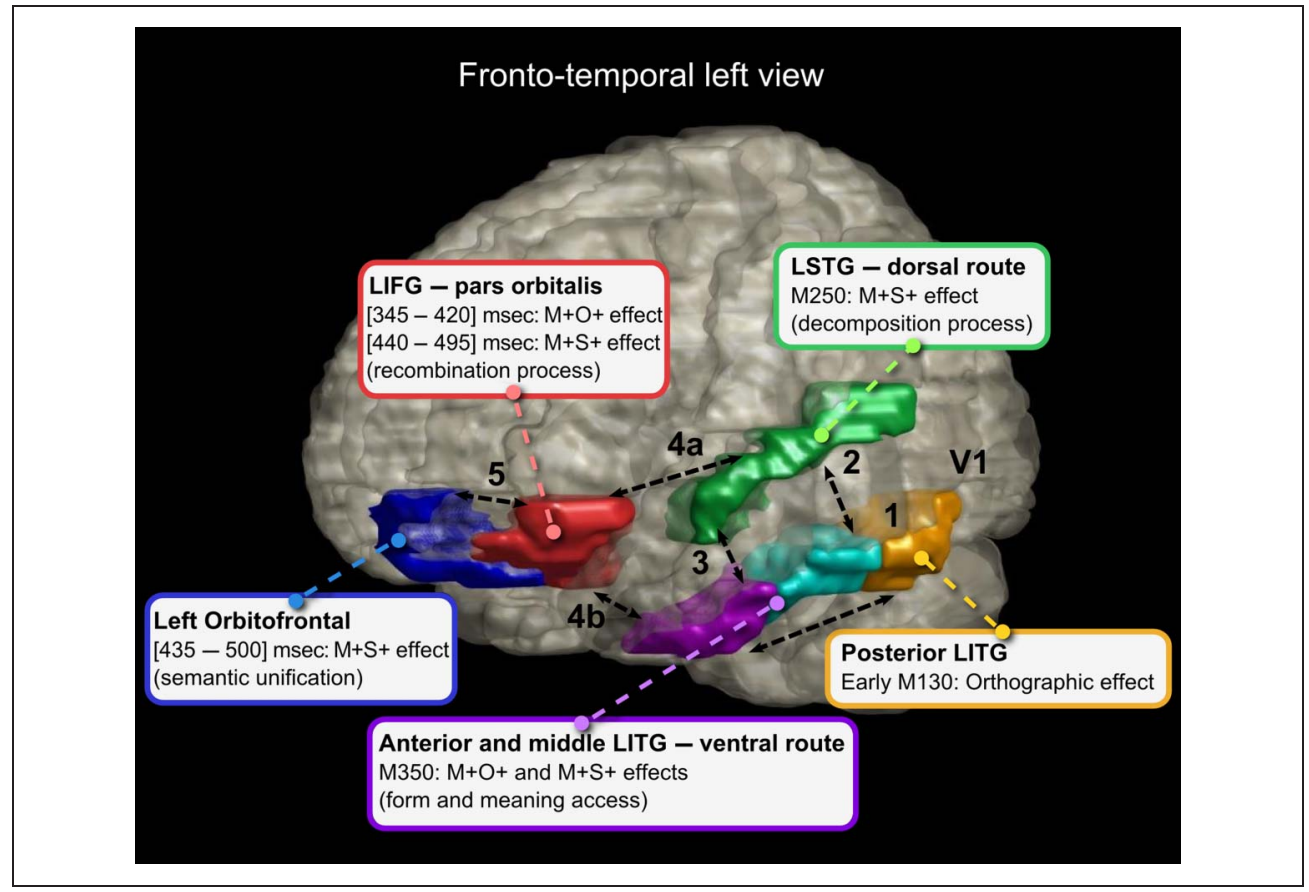


"morphosemantic" processing, because of the lack of a pseudocomplex condition (corner-corn), these results nevertheless suggest that there might be greater interdependence between these processes than previously thought (Feldman et al., 2015). Fourth, the earliest effects of morphology occurred in left superior temporal gyrus around $250 \mathrm{msec}$ and reflected the semantic contribution to morphological facilitation (significant $\mathrm{M}+\mathrm{S}+$ effect in the absence of $\mathrm{M}+\mathrm{O}+$ effects). This finding suggests that when participants are given enough time to process the prime, early morphological effects can be sensitive to semantic overlap.

\section{Acknowledgments}

This work was supported by French Life Imaging (FLI) and Labex BLRI (ANR-11-LABX-0036), managed by the French National Agency for Research (ANR), under the project title Investments of the Future A*MIDEX (ANR-11-IDEX-0001-02). Eddy Cavalli was supported by a grant from the French Ministry of Research (2013-2016).

Reprint requests should be sent to Johannes C. Ziegler or Eddy Cavalli, Laboratoire de Psychologie Cognitive, Aix Marseille Université, 3, place Victor Hugo, Bat 9, Case D, 13331 Marseille Cedex 3, France, or via e-mail: Johannes.ziegler@univ-amu.fr, eddy.cavalli@univ-amu.fr.

\section{Note}

1. Note that the direction of the event-related fields is arbitrary in MEG as it depends on the structural changes in the cerebral cortex. Positive or negative differences cannot be taken as a signature of reduced or increased activation. However, for a given priming effect, it is possible to consider whether the absolute activity of the condition of interest is reduced, regardless of whether it is positive or negative. This can be done by comparing the absolute activity values for the critical condition against the control condition

\section{REFERENCES}

Adams, R. B., \& Janata, P. (2002). A comparison of neural circuits underlying auditory and visual object categorization. Neuroimage, 16, 361-377.

Bemis, D. K., \& Pylkkänen, L. (2013). Basic linguistic composition recruits the left anterior temporal lobe and left angular gyrus during both listening and reading. Cerebral Cortex, 23, 1859-1873.

Benjamini, Y., \& Hochberg, Y. (1995). Controlling the false discovery rate: A practical and powerful approach to multiple testing. Journal of the Royal Statistical Society, Series B, 57, 289-300.

Beyersmann, E., Castles, A., \& Coltheart, M. (2012). Morphological processing during visual word recognition in developing readers: Evidence from masked priming. Quarterly Journal of Experimental Psychology, 65, 1306-1326.

Beyersmann, E., Coltheart, M., \& Castles, A. (2012). Parallel processing of whole words and morphemes in visual word recognition. Quarterly Journal of Experimental Psychology, 65, 1798-1819.

Beyersmann, E., Iakimova, G., Ziegler, J. C., \& Colé, P. (2014). Semantic processing during morphological priming: An ERP study. Brain Research, 1579, 45-55.
Beyersmann, E., Ziegler, J., Castles, A., Coltheart, M., Kezilas, Y., \& Grainger, J. (2015). Morpho-orthographic segmentation without semantics. Psychonomic Bulletin \& Review, 22, $1-7$.

Binder, J. R., Desai, R. H., Graves, W. W., \& Conant, L. L. (2009) Where is the semantic system? A critical review and meta-analysis of 120 functional neuroimaging studies. Cerebral Cortex, 19, 2767-2796.

Bozic, M., Marslen-Wilson, W. D., Stamatakis, E. A., Davis, M. H., \& Tyler, L. K. (2007). Differentiating morphology, form, and meaning: Neural correlates of morphological complexity. Journal of Cognitive Neuroscience, 19, 1464-1475.

Brennan, J., \& Pylkkänen, L. (2008). Processing events: Behavioral and neuromagnetic correlates of aspectual coercion. Brain and Language, 106, 132-143.

Brown, C., \& Hagoort, P. (1993). The processing nature of the N400: Evidence from masked priming. Journal of Cognitive Neuroscience, 5, 34-44.

Cohen, L., Dehaene, S., Naccache, L., Lehericy, S., DehaeneLambertz, G., Henaff, M. A., et al. (2000). The visual word form area-Spatial and temporal characterization of an initial stage of reading in normal subjects and posterior split-brain patients. Brain, 123, 291-307.

Colombet, B., Woodman, M., Bénar, C. G., \& Badier, J. M. (2015). AnyWave: A cross-platform and modular software for visualizing and processing electrophysiological signals. Journal of Neuroscience Methods, 242, 118-126.

Coltheart, M., Rastle, K., Perry, C., Langdon, R., \& Ziegler, J. (2001). DRC: A dual route cascaded model of visual word recognition and reading aloud. Psychological Review, 108, 204-256.

Cornelissen, P. L., Kringelbach, M. L., Ellis, A. W., Whitney, C., Holliday, I. E., \& Hansen, P. C. (2009). Activation of the left inferior frontal gyrus in the first $200 \mathrm{msec}$ of reading: Evidence from magnetoencephalography (MEG). PLoS One, 4, e5359.

Crepaldi, D., Rastle, K., Coltheart, M., \& Nickels, L. (2010). "Fell" primes "fall," but does "bell" prime "ball"? Masked priming with irregularly-inflected primes. Journal of Memory and Language, 63, 83-99.

Davis, M. H., Meunier, F., \& Marslen-Wilson, W. D. (2004). Neural responses to morphological, syntactic, and semantic properties of single words: An fMRI study. Brain and Language, 89, 439-449.

Dehaene, S., Cohen, L., Sigman, M., \& Vinckier, F. (2005). The neural code for written words: A proposal. Trends in Cognitive Sciences, 9, 335-341.

Dehaene, S., Le Clec, H. G., Poline, J. B., Le Bihan, D., \& Cohen, L. (2002). The visual word-form area: A prelexical representation of visual words in the fusiform gyrus. NeuroReport, 13, 321-325.

Devlin, J. T., Jamison, H. L., Matthews, P. M., \& Gonnerman, L. M. (2004). Morphology and the internal structure of words. Proceedings of the National Academy of Sciences, U.S.A. 101, 14984-14988.

Diependaele, K., Sandra, D., \& Grainger, J. (2005). Masked cross-modal morphological priming: Unravelling morphoorthographic and morphosemantic influences in early word recognition. Language and Cognitive Processes, 20, 75-114.

Diependaele, K., Sandra, D., \& Grainger, J. (2009). Semantic transparency and masked morphological priming: The case of prefixed words. Memory \& Cognition, 37, 895-908.

Feldman, L. B. (2000). Are morphological effects distinguishable from the effects of shared meaning and shared form? Journal of Experimental Psychology: Learning, Memory, and Cognition, 26, 1431-1444. 
Feldman, L. B., Milin, P., Cho, K. W., Moscoso del Prado Martín, F., \& O'Connor, P. A. (2015). Must analysis of meaning follow analysis of form? A time course analysis. Frontiers in Human Neuroscience, 9, 1-19.

Feldman, L. B., O'Connor, P. A., \& Moscoso del Prado Martin, F. (2009). Early morphological processing is morphosemantic and not simply morpho-orthographic: A violation of form-then-meaning accounts of word recognition. Psychonomic Bulletin \& Review, 16, 684-691.

Friederici, A. D. (2011). The brain basis of language processing: From structure to function. Physiological Reviews, 91, $1357-1392$

Fruchter, J., \& Marantz, A. (2015). Decomposition, lookup, and recombination: MEG evidence for the Full Decomposition model of complex visual word recognition. Brain and Language, 143, 81-96.

Gold, B., \& Rastle, K. (2007). Neural correlates of morphological decomposition during visual word recognition. Journal of Cognitive Neuroscience, 19, 1983-1993.

Gross, J., Baillet, S., Barnes, G. R., Henson, R. N., Hillebrand, A., Jensen, O., et al. (2013). Good practice for conducting and reporting MEG research. Neuroimage, 65, 349-363.

Hagoort, P. (2005). On Broca, brain, and binding: A new framework. Trends in Cognitive Sciences, 9, 416-423.

Harpaz, Y., Lavidor, M., \& Goldstein, A. (2013). Right semantic modulation of early MEG components during ambiguity resolution. Neuroimage, 82, 107-114.

Helenius, P., Salmelin, R., Service, E., \& Connolly, J. F. (1998). Distinct time courses of word and context comprehension in the left temporal cortex. Brain, 121, 1133-1142.

Holme, C. J., Hoge, R., Collins, L., Woods, R., Toga, A. W., \& Evans, A. C. (1998). Enhancement of MR images using registration for signal averaging. Journal of Computer Assisted Tomography, 22, 324-333.

Jobard, G., Crivello, F., \& Tzourio-Mazoyer, N. (2003). Evaluation of the dual route theory of reading: A metanalysis of 35 neuroimaging studies. Neuroimage, 20, 693-712.

Lavric, A., Clapp, A., \& Rastle, K. (2007). ERP evidence of morphological analysis from orthography: A masked priming study. Journal of Cognitive Neuroscience, 19, 866-877.

Lavric, A., Elchlepp, H., \& Rastle, K. (2012). Tracking hierarchical processing in morphological decomposition with brain potentials. Journal of Experimental Psychology: Human Perception and Performance, 38, 811-816.

Lavric, A., Rastle, K., \& Clapp, A. (2011). What do fully visible primes and brain potentials reveal about morphological decomposition? Psychophysiology, 48, 676-686.

Lewis, G., Solomyak, O., \& Marantz, A. (2011). The neural basis of obligatory decomposition of suffixed words. Brain and Language, 108, 191-196.

Longtin, C. M., \& Meunier, F. (2005). Morphological decomposition in early visual word processing. Journal of Memory and Language, 53, 26-41.

Maris, E., \& Oostenveld, R. (2007). Nonparametric statistical testing of EEG- and MEG-data. Journal of Neuroscience Methods, 164, 177-190.

Meunier, F., \& Longtin, C. M. (2007). Morphological decomposition and semantic integration in word processing Journal of Memory and Language, 56, 457-471.

Montant, M., Schön, D., Anton, J. L., \& Ziegler, J. C. (2011). Orthographic contamination of Broca's area. Frontiers in Psychology, 2, 1-10.

Morris, J., Frank, T., Grainger, J., \& Holcomb, P. J. (2007). Semantic transparency and masked morphological priming: An ERP investigation. Psychophysiology, 44, 506-521.

Morris, J., Grainger, J., \& Holcomb, P. J. (2008). An electrophysiological investigation of early effects of masked morphological priming. Language and Cognitive Processes, 23, 1021-1056.

Morris, J., Grainger, J., \& Holcomb, P. J. (2013). Tracking the consequences of morpho-orthographic decomposition using ERPs. Brain Research, 1529, 92-104.

Morris, J., Porter, J. H., Grainger, J., \& Holcomb, P. J. (2011). Effects of lexical status and morphological complexity in masked priming: An ERP study. Language and Cognitive Processes, 26, 558-599.

Noppeney, U., \& Price, C. J. (2003). Functional imaging of the semantic system: Retrieval of sensory-experienced and verbally learned knowledge. Brain and Language, 84, $120-133$

Oostenveld, R., Fries, P., Maris, E., \& Schoffelen, J. M. (2011). FieldTrip: Open source software for advanced analysis of MEG, EEG, and invasive electrophysiological data. Computational Intelligence and Neuroscience, 2011, 156869.

Pastizzo, M. J., \& Feldman, L. B. (2009). Boats prime float but coats don't: Priming from nonmorphological form and meaning similarity invites a computational account of morphological processing. The Mental Lexicon, 4, 1-25.

Price, C. J. (2012). A review and synthesis of the first 20 years of PET and fMRI studies of heard speech, spoken language and reading. Neuroimage, 62, 816-847.

Pylkkänen, L., Feintuch, S., Hopkins, E., \& Marantz, A. (2004). Neural correlates of the effects of morphological family frequency and size: A MEG study. Cognition, 91, B35-B45.

Pylkkänen, L., \& Marantz, A. (2003). Tracking the time course of word recognition with MEG. Trends in Cognitive Sciences, 7, 187-189.

Pylkkänen, L., \& McElree, B. (2007). An MEG study of silent meaning. Journal of Cognitive Neuroscience, 19, 126-149.

Pylkkänen, L., Oliveri, B., \& Smart, A. J. (2009). Semantics vs. world knowledge in prefrontal cortex. Language and Cognitive Processes, 24, 1313-1334.

Pylkkänen, L., Stringfellow, A., \& Marantz, A. (2002). Neuromagnetic evidence for the timing of lexical activation: An MEG component sensitive to phonotactic probability but not to neighborhood density. Brain and Language, 81, 666-678.

Rastle, K., \& Davis, M. H. (2008). Morphological decomposition based on the analysis of orthography. Language and Cognitive Processes, 23, 942-971.

Rastle, K., Davis, M. H., Marslen-Wilson, W. D., \& Tyler, L. K. (2000). Morphological and semantic effects in visual word recognition: A time-course study. Language and Cognitive Processes, 15, 507-537.

Raven, J., \& Court, J. (1995). Standard progressive matrices series $A, B, C, D, E$ (revised 1956). Paris: Editions Techniques et Psychotechniques.

Rey-Debove, J. (1984). Le domaine de la morphologie lexicale [The domain of lexical morphology]. Cahiers de Lexicologie, 45, 3-19.

Smolka, E., Gondan, M., \& Rösler, F. (2015). Take a stand on understanding: Electrophysiological evidence for stem access in German complex verbs. Frontiers in Human Neuroscience, 9, 62.

Solomyak, O., \& Marantz, A. (2010). Evidence for early morphological decomposition in visual word recognition. Journal of Cognitive Neuroscience, 22, 2042-2057.

Taft, M. (1979). Recognition of affixed words and the word frequency effect. Memory and Cognition, 7, 263-272. 
Tzourio-Mazoyer, N., Landeau, B., Papathanassiou, D., Crivello, F., Etard, O., Delcroix, N., et al. (2002). Automated anatomical labeling of activations in SPM using a macroscopic anatomical parcellation of the MNI MRI single-subject brain. Neuroimage, 15, 273-289.

Vartiainen, J., Aggujaro, S., Lehtonen, M., Hultén, A., Laine, M., \& Salmelin, R. (2009). Neural dynamics of reading morphologically complex words. Neuroimage, 47, 2064-2072.

Vinckier, F., Dehaene, S., Jobert, A., Dubus, J. P., Sigman, M., \& Cohen, L. (2007). Hierarchical coding of letter strings in the ventral stream: Dissecting the inner organization of the visual word-form system. Neuron, 55, 143-156.

Wagner, A. D., Koutstaal, W., Maril, A., Schacter, D. L., \& Buckner, R. L. (2000). Task-specific repetition priming in left inferior prefrontal cortex. Cerebral Cortex, 10, 1176-1184.

Whiting, C., Shtyrov, Y., \& Marslen-Wilson, W. (2015). Real-time functional architecture of visual word recognition. Journal of Cognitive Neuroscience, 27, 246-265. 